\title{
VISUAL EXPERIENCE (VISUAL SEQUENCES) OF QAIETBAI CASTLE IN ALEXANDRIA IN THE NATURAL AND BUILT CONTEXT
}

\section{Fatma Othman Mohamed Othman}

A Lecturer in Architectural and Civil Construction Department Faculty of Industrial Education - Sohag University

(Received October 16, 2010 Accepted November25, 2010)

Qaietbai Castle in Alexandria is one of the most important Islamic monuments that possesses a unique position according to the city's built context as it gathers between the natural component that are represented in the heaven space and aqua surface, as well as its other activities on the hand, and the built context represented in the surrounding urbanized areas with their visual components on the other.

This paper aims at studying the possibility of upgrading aesthetic image level, and achieving a higher positive level of visual realization of historical places as well as investing this in urbanized built upgrading of valuable historical building, and other surrounding areas through reaching ordered systematic steps that enable us to achieve a higher level of visual realization of heritage building through its visual richness and surrounding areas, and prevent confusion that contributes to reducing visual realization.

This study depended on descriptive and analytical approach through studying the most important elements that affect visual richness and realization of historical places, through describing and analyzing the case study of Qaietbai Castle in Alexandria to specify the problems faced by valuable monumental places

So the study was conducted to investigate the visual experience to realize the castle on the way to the beach of Alexandria city through dividing it into sectors of sight to study the visual sequence towards the castle, the possibility of its visual richness, and the visual experience inside the castle, its neighborhoods and the surrounding urbanized environment.

The study showed the importance of visual studies in Egyptian cities, enriching urban and archeological areas, and not neglecting or considering them secondary things especially in the archeological regions, and taking serious steps to prevent visual aggressiveness in all its kinds to create interaction between the receiver and the visual environment of heritage zone that should be in the mind of the visitor as an unforgettable visual experience. As for the city inhabitant, his interaction with the visual environment in his city does strengthen his belonging to the city, and encourages him to converse its heritage zones. They are all positive values we wish to enhance, converse, and strengthen.

The research consists of four parts, the first part deals with the problem of research and its methods, the second part is a theatrical introduction 
to visual realization of heritage and historical areas in the built context and environmental surroundings, as well as the most important means that leads to visual richness of such areas . the third part deals with a study of the visual experience to realize the building of Qaietbai Castle, the possibility of its visual richness and giving the surrounding area a unique visual character due to the visual reference represented in the building of the castle. The fourth part deals with the concluded results.

\title{
التجربة البصرية (المتتابعة البصرية ) لقلعة قايتباي بالإسكندرية في المحيط العمراني والطبيعي
}

\author{
د فاطمة عثمان محمد عثمان \\ مدرس بقسم الانثاءت المعمارية و المدنية ـكلية التعليم الصناعي -جامعة سو هاج \\ e-mail fatma_ossman@hotmail.com
}

ملخص البحث

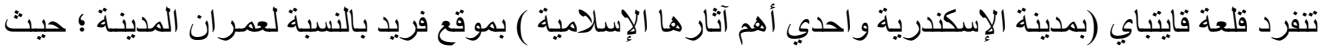

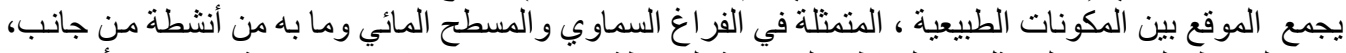

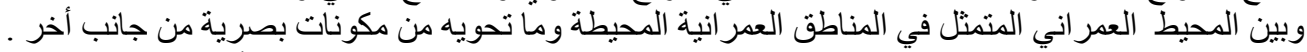

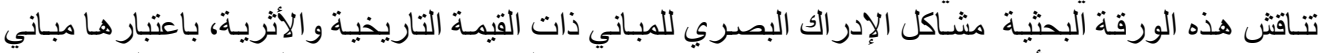

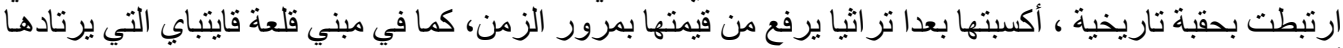

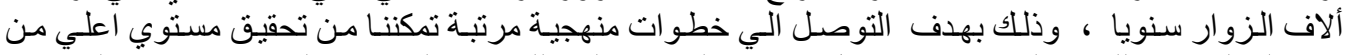

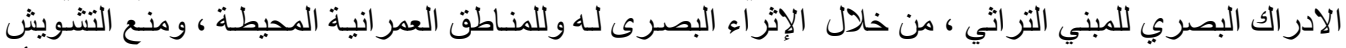

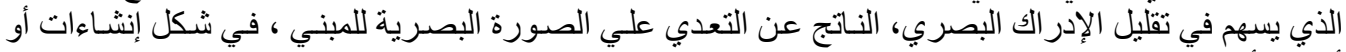

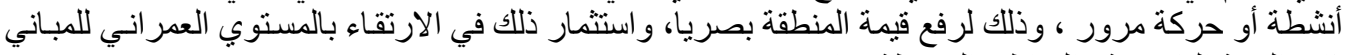

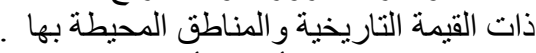

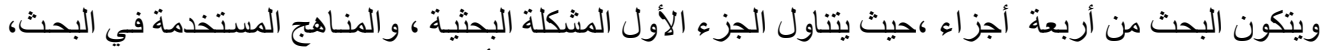

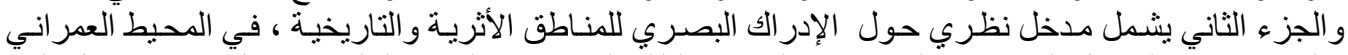

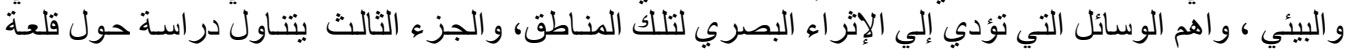

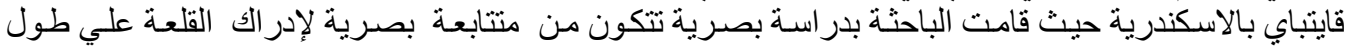

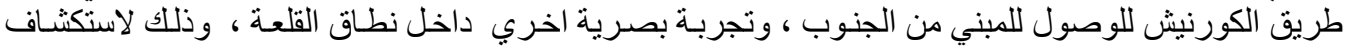

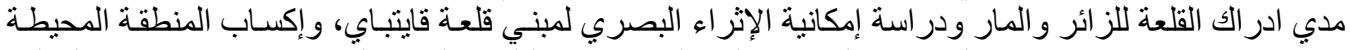

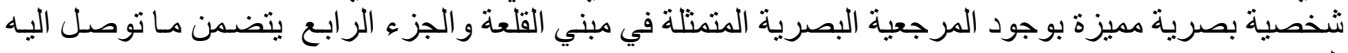
البحث من نتائج.

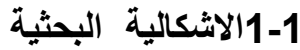

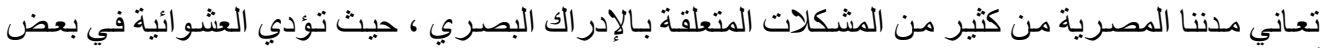

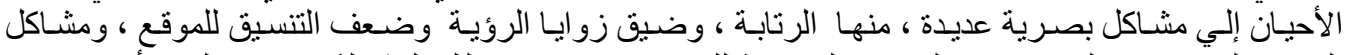

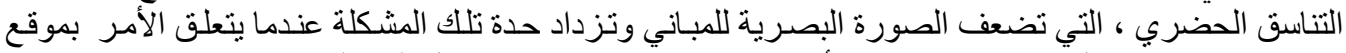

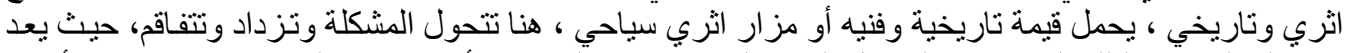

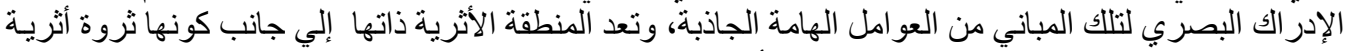

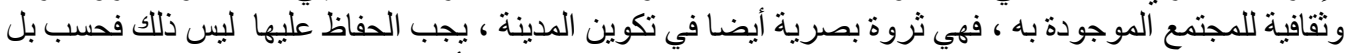

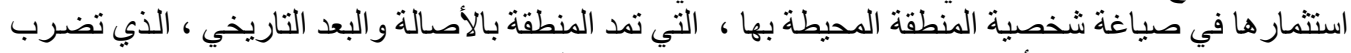
جذوره في تاريخ ونقافة الأمة وحاضر ها وتسهم في صياغة مستقبلها. 


\section{2-1 هدف الاراسة}

وتهدف هذه الورقة البحثية إلي دراسة إمكانية الارتقاء بمستوي الصورة الجمالية ،وتحقيق مستوي اعلي ايجابية

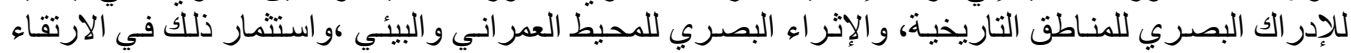

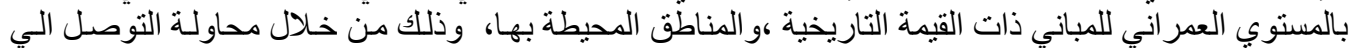

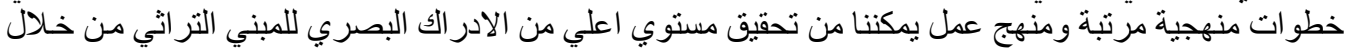

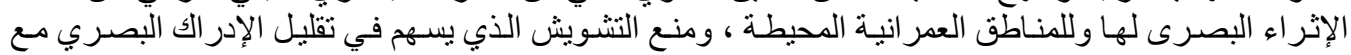
در اسة قلعة قايتباي كمثال لذلك الكئ.

\section{1- 3 منهج البحث}

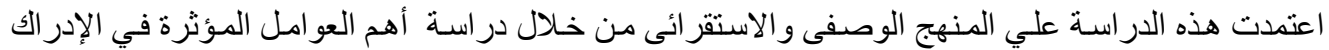

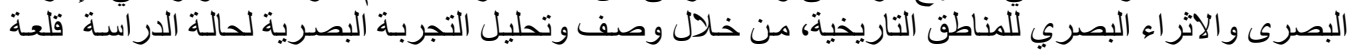

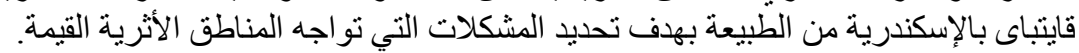

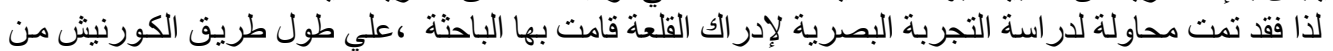

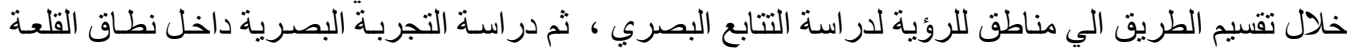

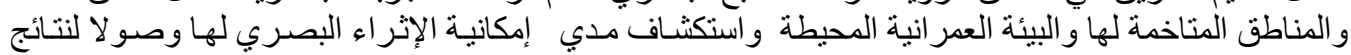

\section{2- مدخل نظري} الدراسة

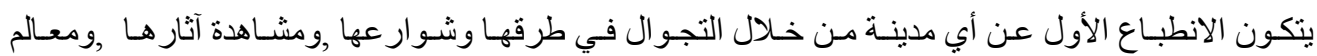

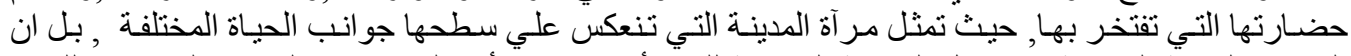

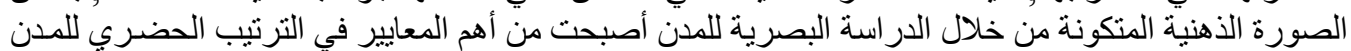
عالميا.

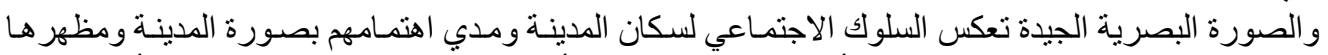

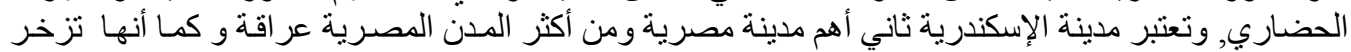

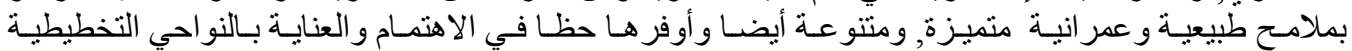
و العمر انية و التنظيمية .

\section{1-2 1الإدراك البصري للمناطق الأثرية والتاريخية}

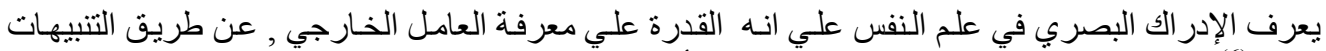

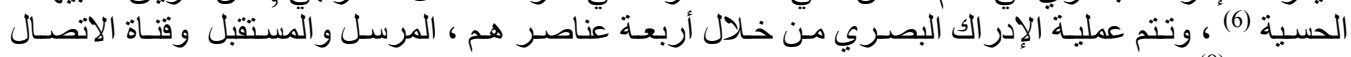

و السياق .

المرسل و هو العنصر المدرك وطبيعته وما يحويه من ممبزات تشكيلية, كالسيطرة و التقرد أو البساطة .

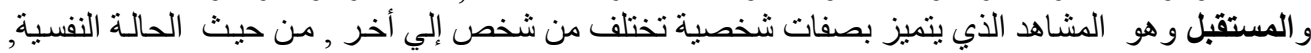

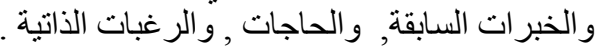

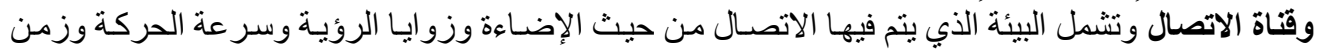

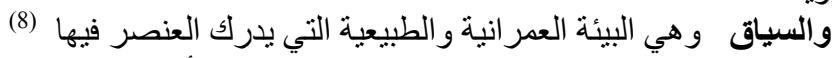

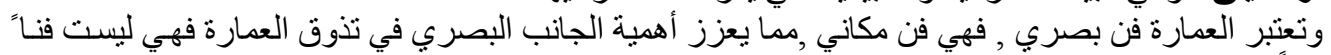

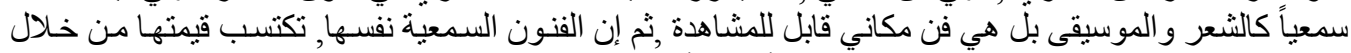

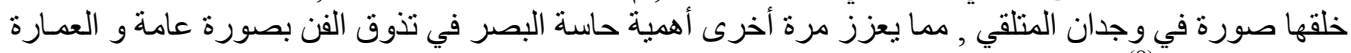

بصورة خاصة. 


\section{visual richness}

معنى الإثراء في اللغة هو الكثرة أو النمو، أما الإثراء البصري يمكن تعريفه بأنه التنوع في التجربة الثعورية

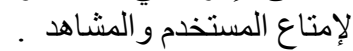

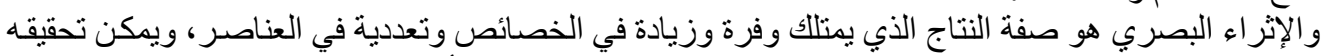

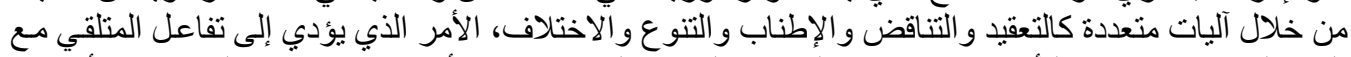

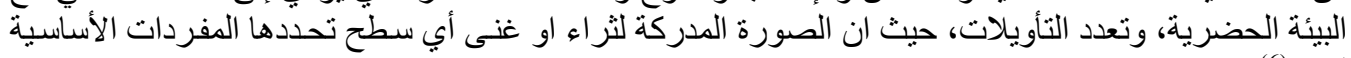

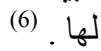
ويعد الإثراء البصري من أهم قيم التصميم البصري، و التي نتمل إلي جانب الإثراء البصري ، عدة قيم أخري

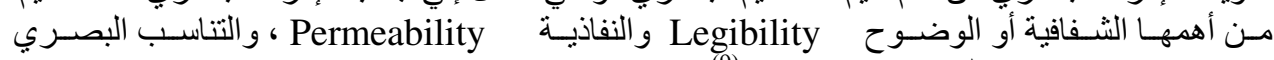

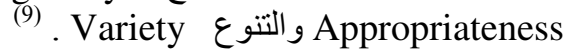

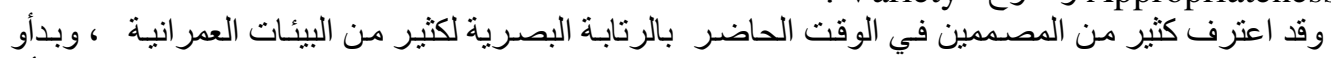

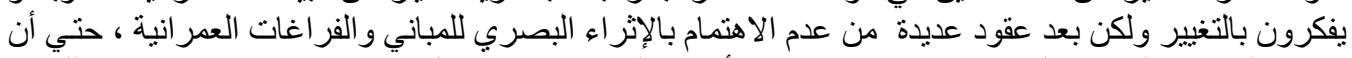

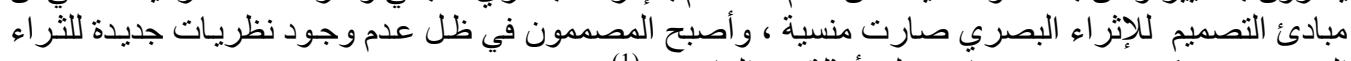

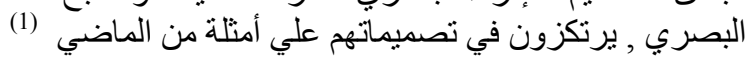

\section{2- 3 العوامل المؤثرة علي الإثراء البصري للمناطق التاريخية}

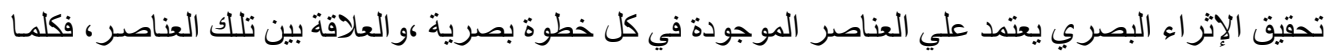

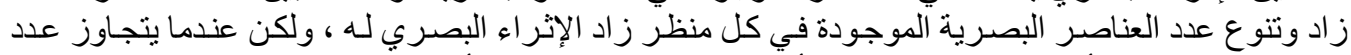

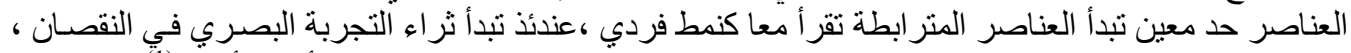

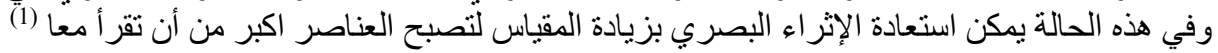

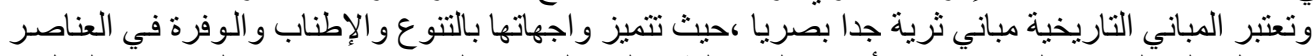

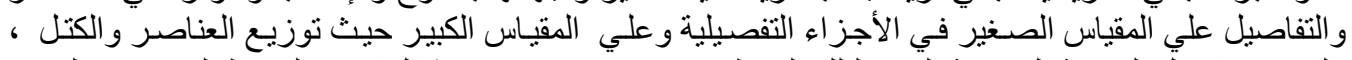

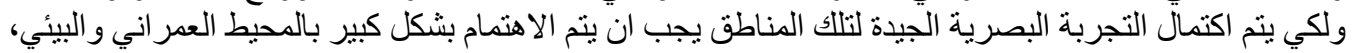

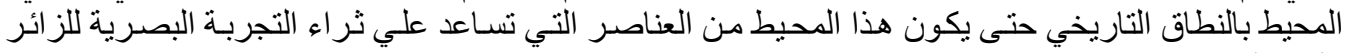
وليستمد الإثكر اء البصري للنطاقات العمر انية والتاريخية علي عاملين أساسيين هما :-

1-3-2

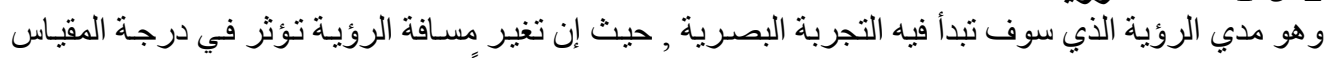

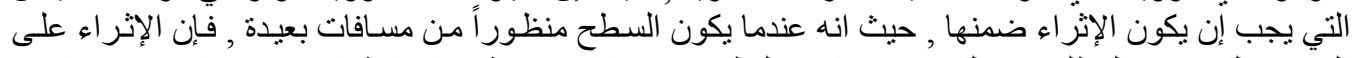

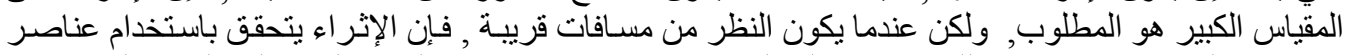

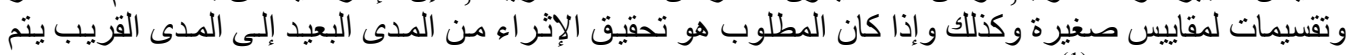

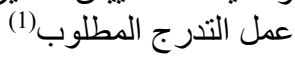

2-3-2 ن زمن الروئية

عندما يكون من الضرون الروية إندي رؤية سطح من موضع معين لفترة طويلة, فأنه من المهم أن يكون السطح مستمراً

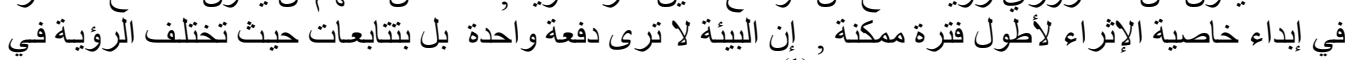

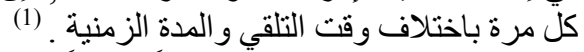

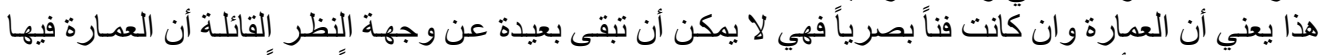

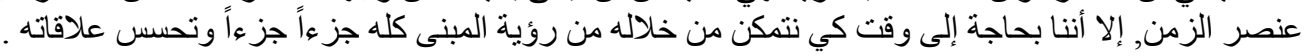

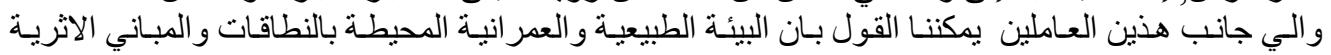

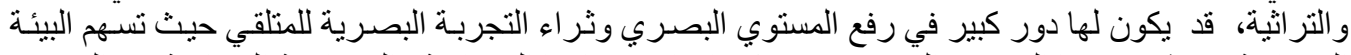

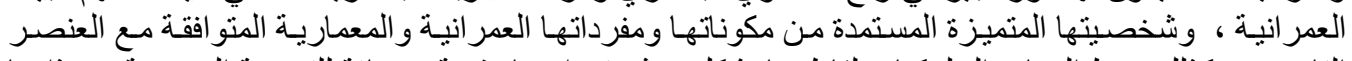

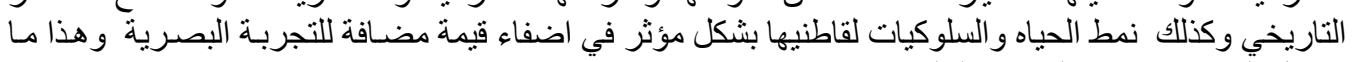
نحاول الكثف عنه في الدراسة التالية . 


\section{3- قلعة قايتباي}

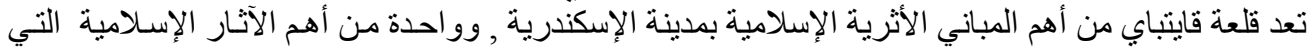

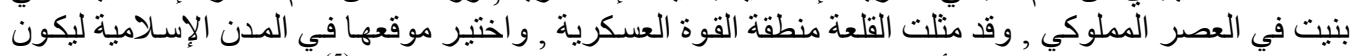

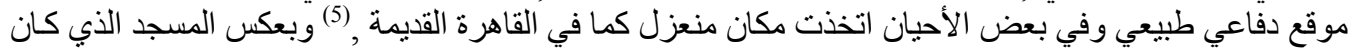

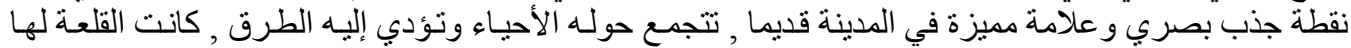

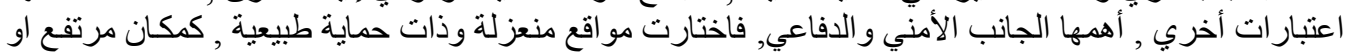

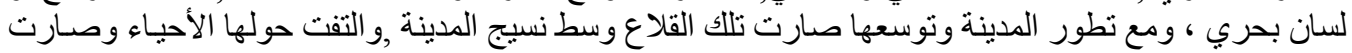
تلعب دور ا هاما في الصورة الذور الذهنية للمناطق المتو اجدة فيها .
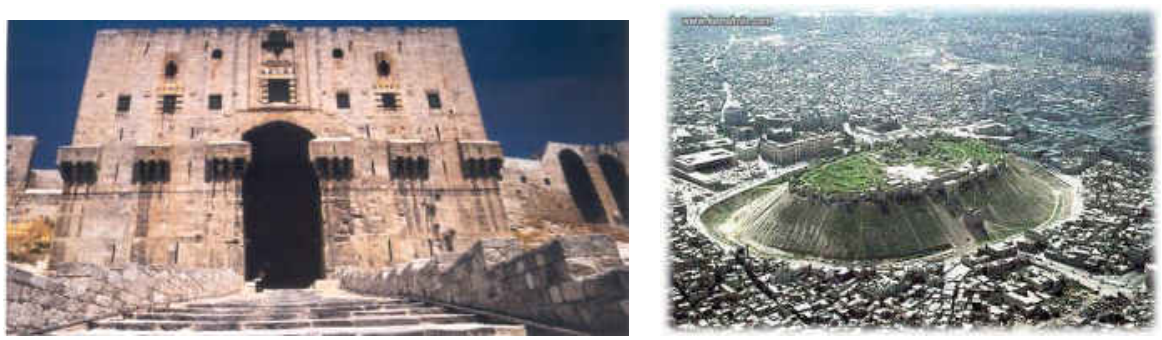

(أ)قلعة حلب الموقع العام وو اجهة احدي البوابات (14)
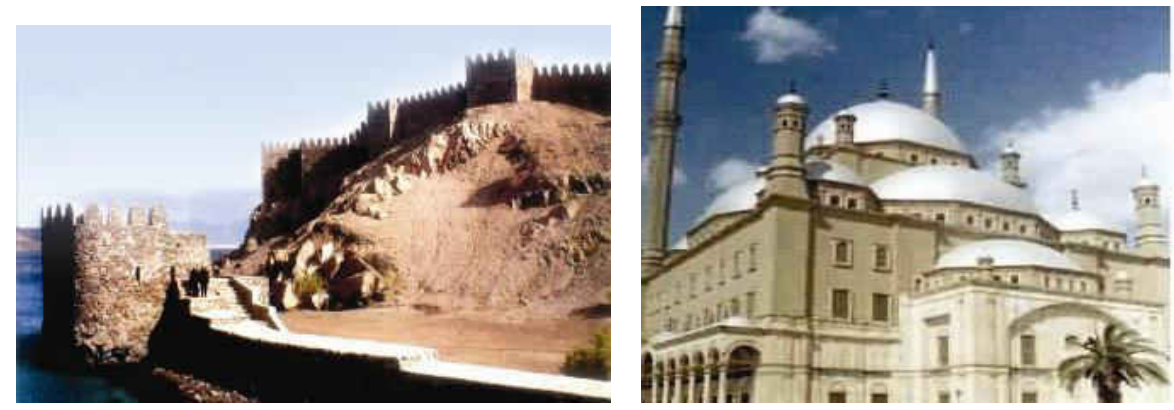

(ب)قلعتي صلاح الدين بالقاهرة وسيناء (12)

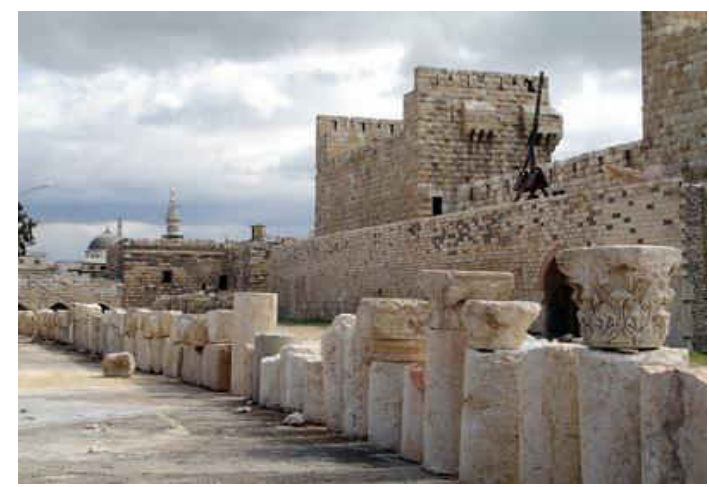

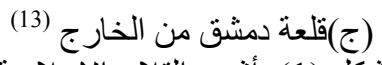

شكل (1) أثنهر القلاع الإسلامية

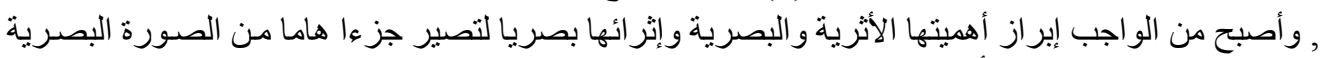

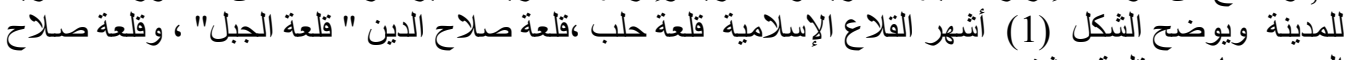
الدين بسيناء ، وقلعة دمشق. 


\section{1-3 التعريف بقلعة قايتباي}

أنثأت القلعة في عام 882 هجرية الموافق 1477 ميلادية , في موقع المنار القديم عند الطرف الثرافي الثرفي لجزيرة

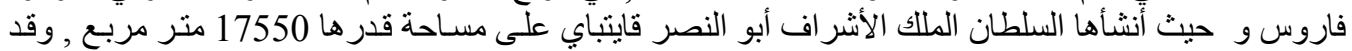

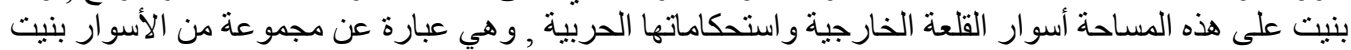

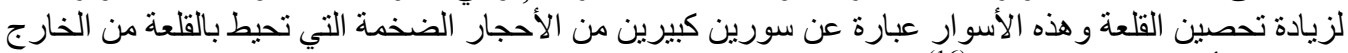

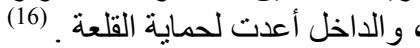

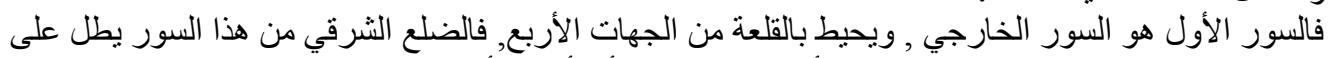

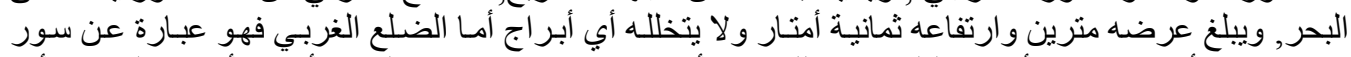

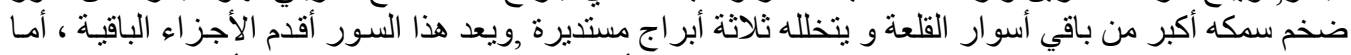

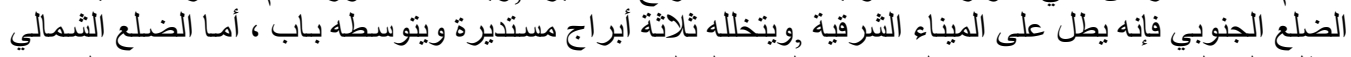

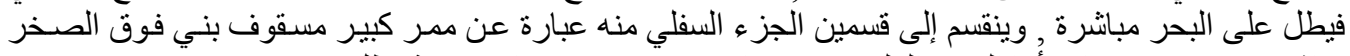

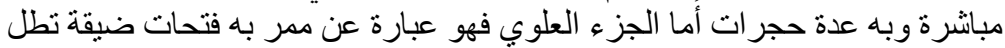

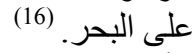

الأسوار الداخلية بينت من الحجر , وتحيط بالبرج الرئيسي من جميع جهاته ما عدا الجهة الثمالية , ويتخلل هذا

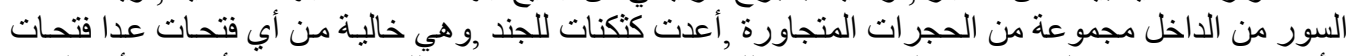

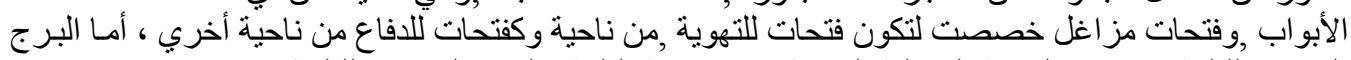

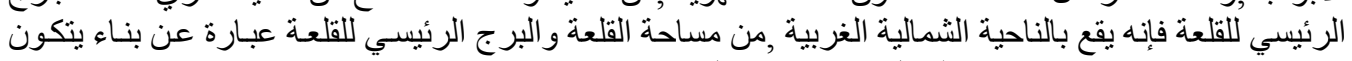

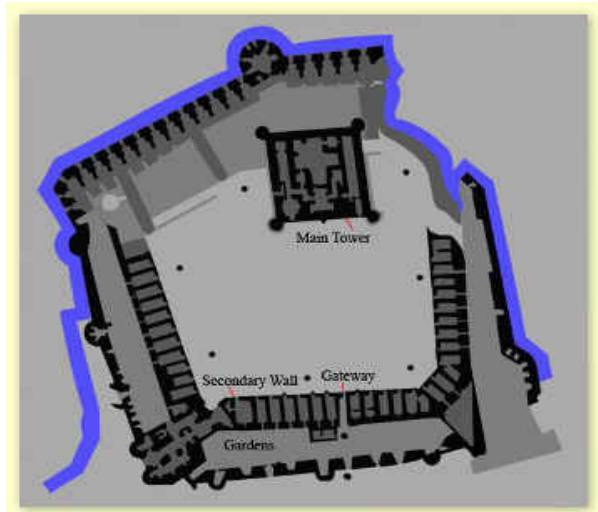

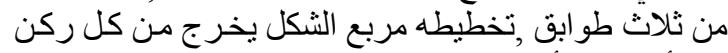

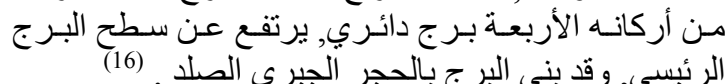

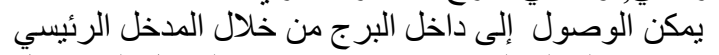

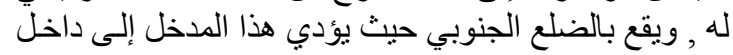

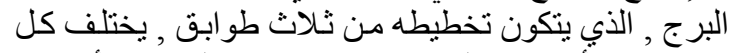

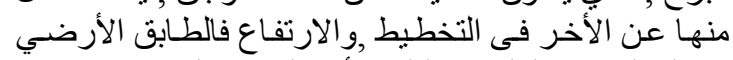

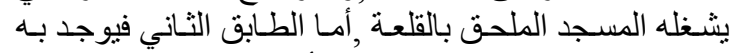

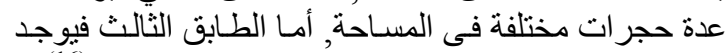

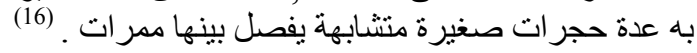

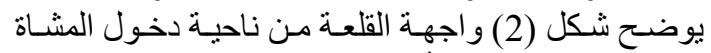

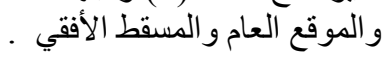

يوضح مكونات القلعة واسوار ها (15)

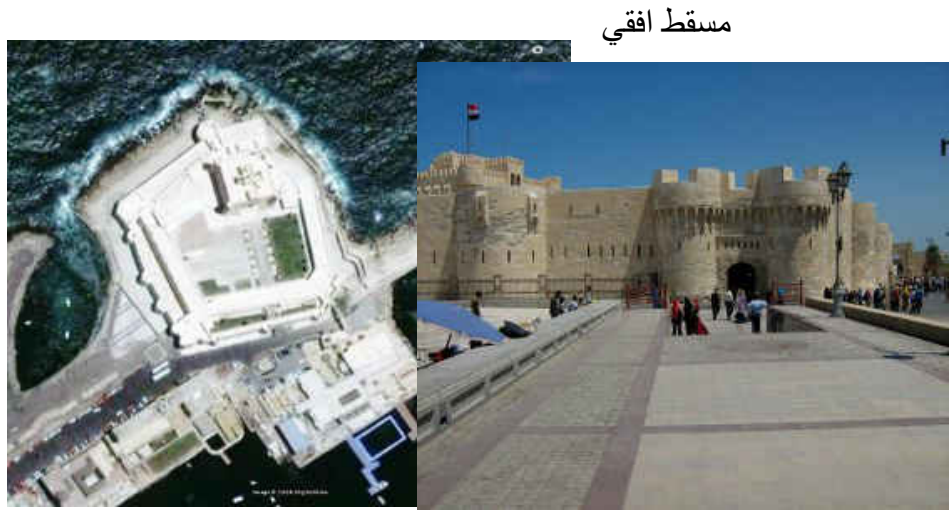

(1) (ج) موقع عام (17)

(ب) و اجهة القلعة (تصوير الباحثة)

شكل (2) مسقط افقي وو اجهه وموقع عام لقلعة قايتباي بالاسكندرية . 


\section{2-3 قيمة الموقع وتميزه}

ولقد اتخذت قلعة قايتباي موقعا فريدا رحيث يجمع بين القيم الطبيعية والتراث الثقافي معا ، حيث يضيف كلا منهما

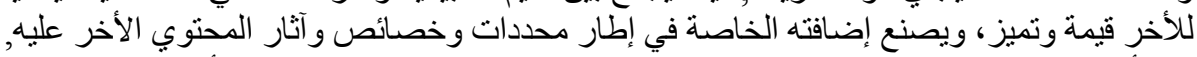

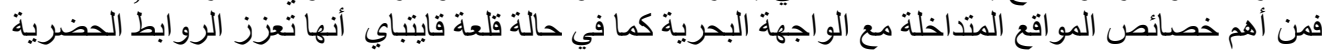

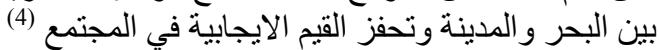

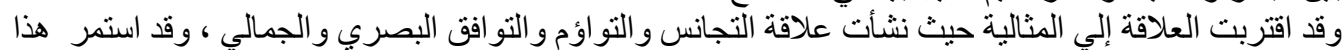

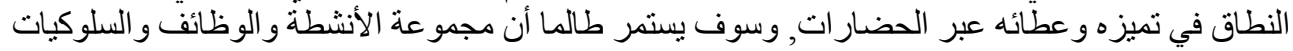

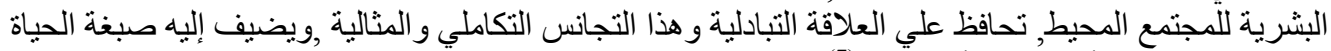

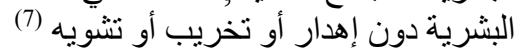

\section{3-3 مشاكل الإدراك البصري للمناطق الأثرية تطبيقا علي قلعة قايتباي}

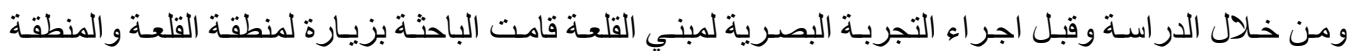

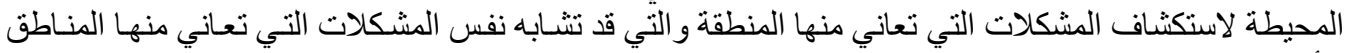

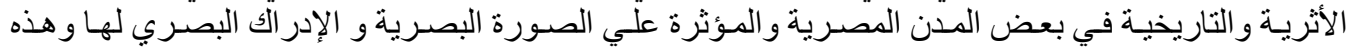
المشكلات بمكن إيجاز ها في الأتي:-

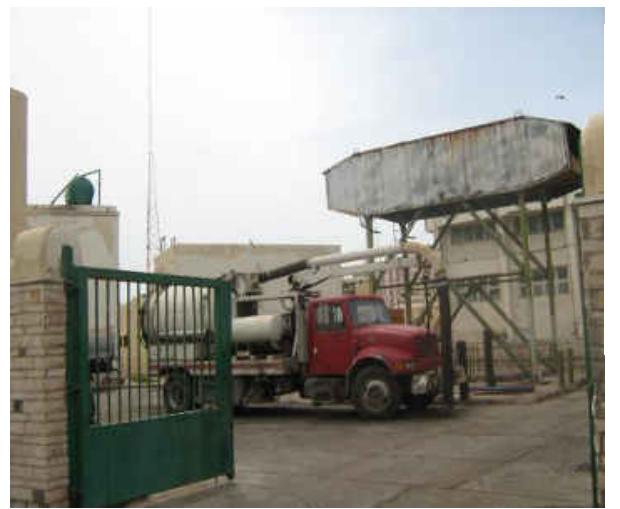

شكل (3) الاستخدامات غير المر غوبة المحيطة بمبني

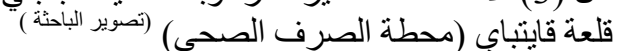

\section{1-3-3 مشاكل تتعلق باستعمالات الأراضي المحيطة}

وتتلخص هذه المشاكل في مدي الاهنمـام بالنطاقات العمر انيـة

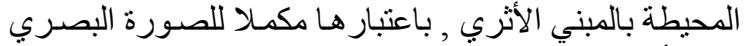

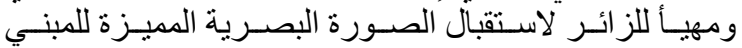

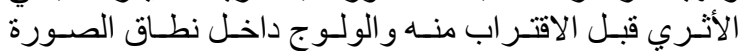

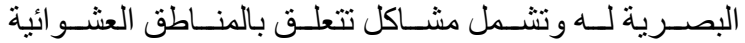

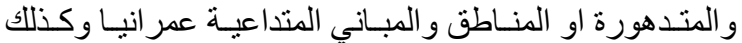

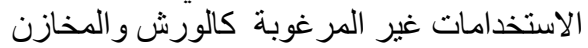

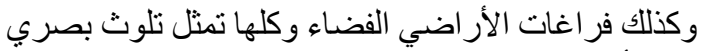

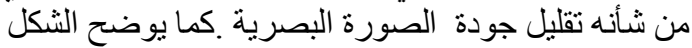
(3) الاستخدامات غير المرغوبة المحيطة بمبني قلعة قايتباي

و هو منشأت خاصة بالهيئة العامة للصرف الصحي

\section{3-3 -3 مشاكل تتعلق بمسارات الحركة}

وتثمل تداخل حركة السيار ات مع حركة المشاة داخل النطاق المؤدي للمبني التاريخي حيث يؤدي هذا إلي إلي

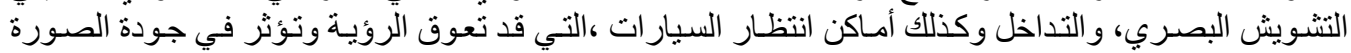
التشويش علي الصورة البص، والبدرية شكل (4).
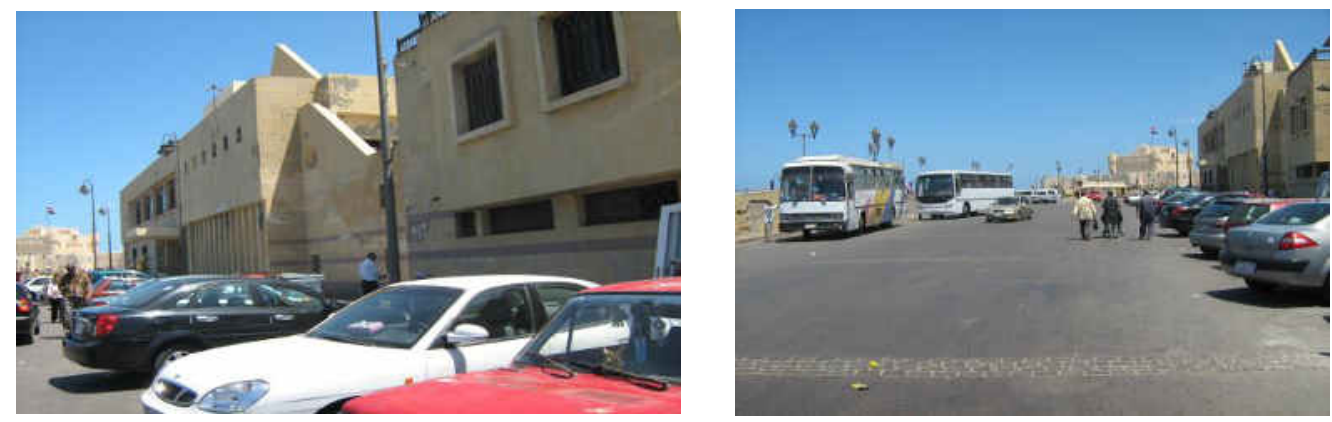

شكل (4) التداخل في حركة المشاة و السيار اتئ و أماكن الانتظار حول قلعة قايتباي 


\section{3-3 - 3-3 -3 مشاكل تتعلق بالروئة}

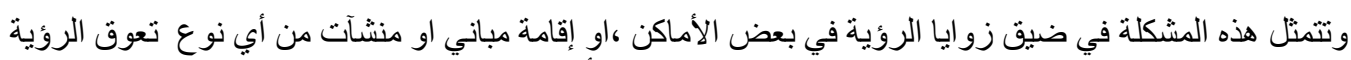

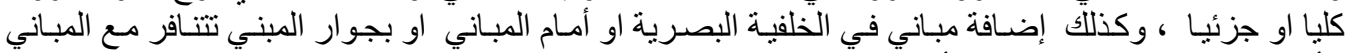
الأثرية، من حيث التصميمات والألوان و النّب تئدي الني الي إضعاف الصورة البصرية شكل (5) .
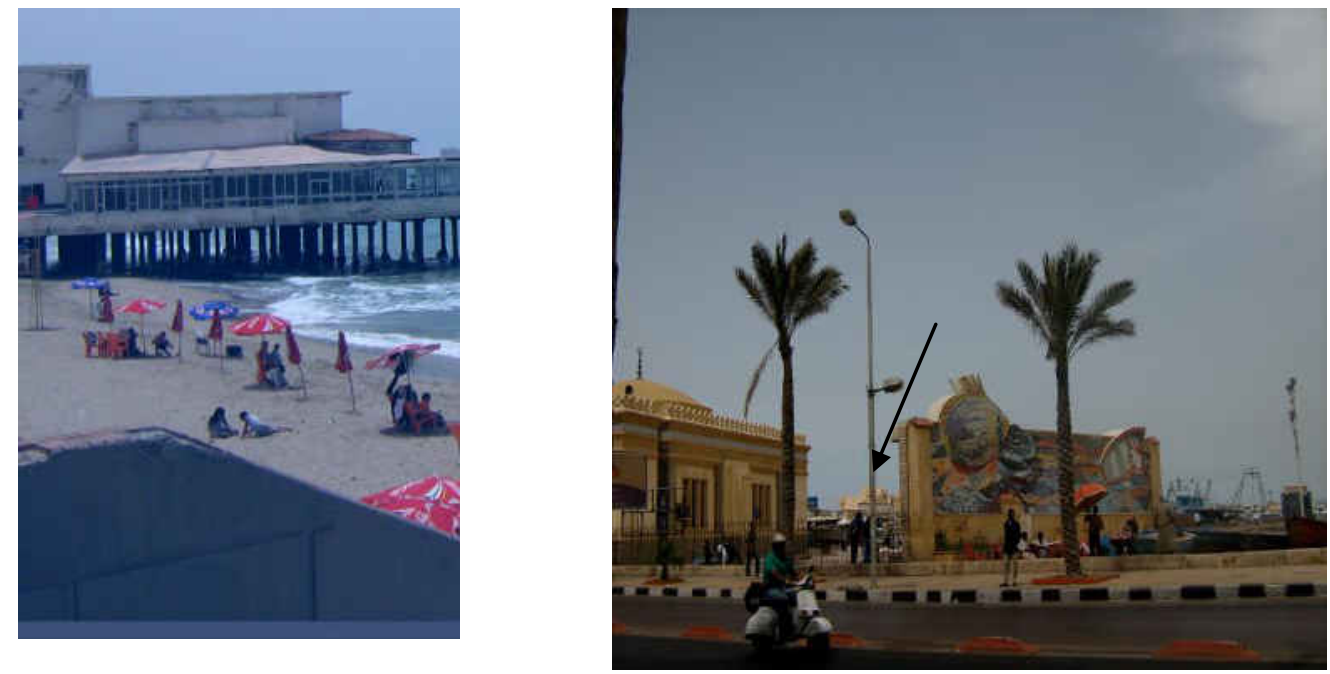

شكل (5) ضيق زو ايا الروية في بعض (الألماكنئ وبناء المنشآت التي تعوق رؤية القلعة.

3-3 -3 مشاكل تتعلق بتنسيق الموقع للمبني الأثري

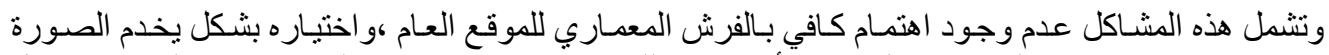

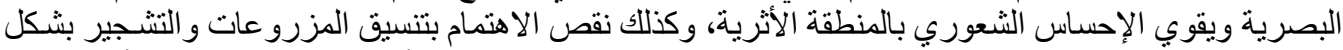

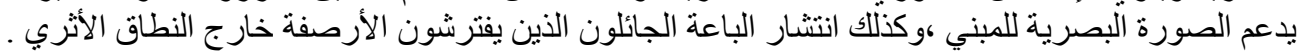

\section{4-3 الدراسة البصرية لمبني قلعة قايتباي في المحيط البيئي والعمراني}

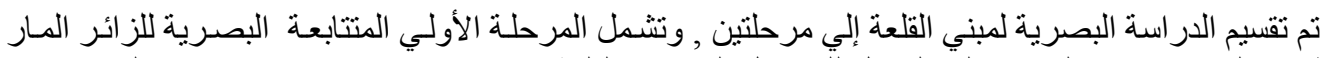

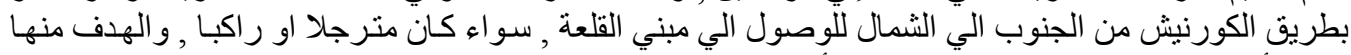

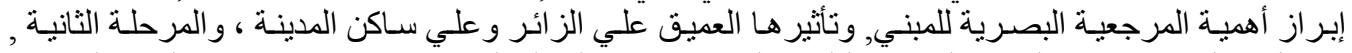

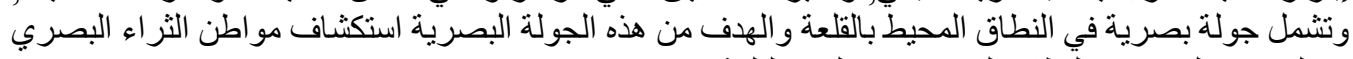

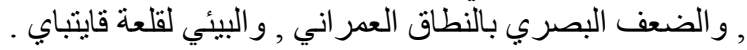

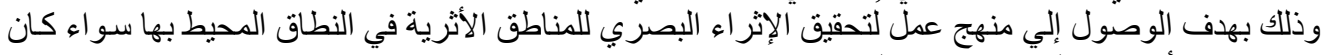
بيئيا وعمر انيا أو كان نطاقا عمر انيا فقط. 
3- 4 المتتابعة البصرية لمبني قلعة قايتباي علي طريق الكورنيش

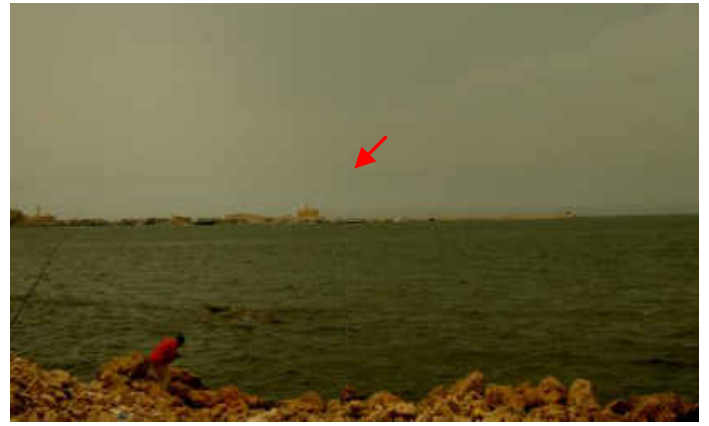

2-1 الإدراك البصري

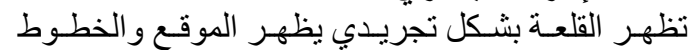

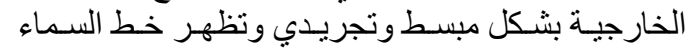

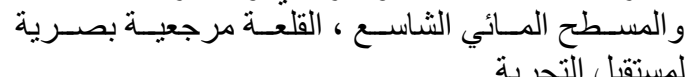

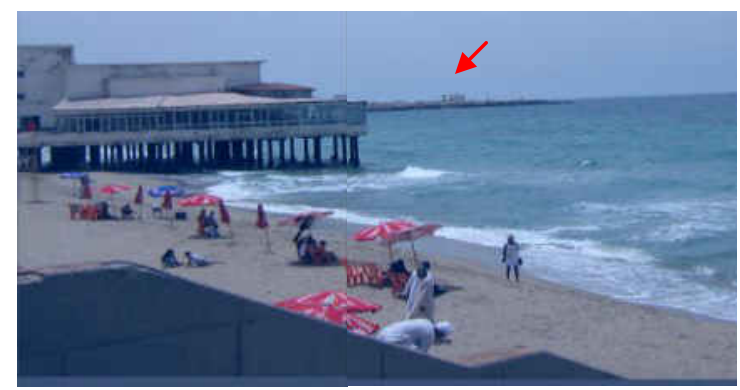

2-2 2-2 الإدرالك البصري

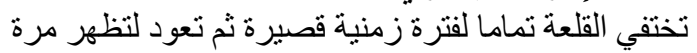
اخري بشكل تجريدي بلا تفاصيل و اضحة

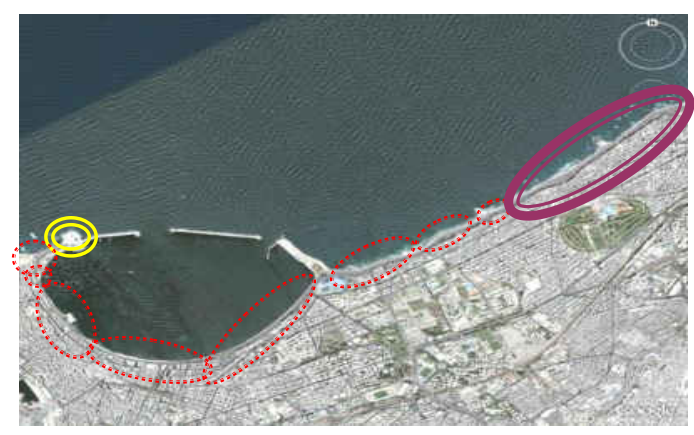

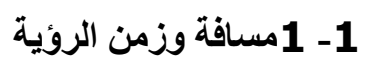

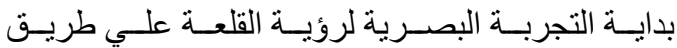

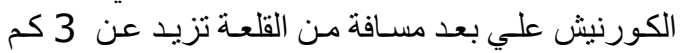

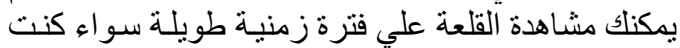

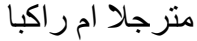

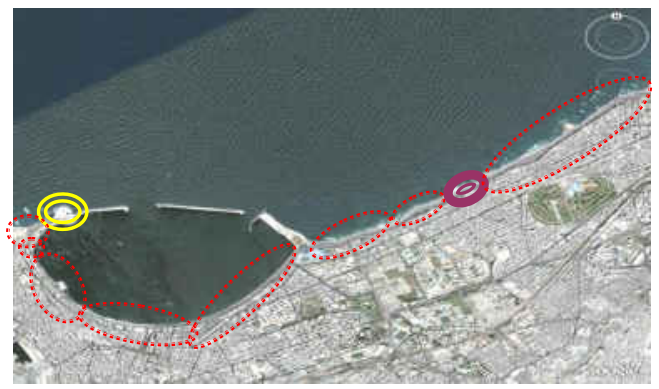

1-2 1-2 مسافة وزمن الروئية

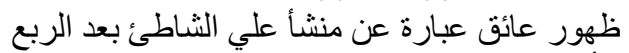

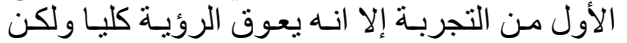

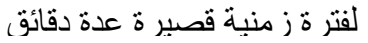

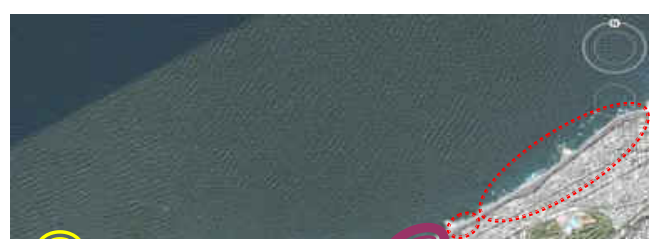

3-3 1- 3مسافة وزمن الروئية

2-3 الإدرالك البصري

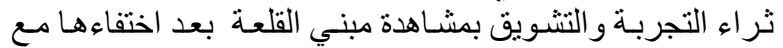
وضوح تدريجي للكتل وظهور أجزاء من اللسان البحري

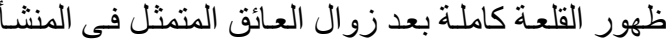

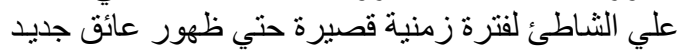
للاؤية وهو اللسان البحري للميناء الثرقي طي 
4-3 المتتابعة البصرية لمبني قلعة قايتباي علي طريق الكورنيش

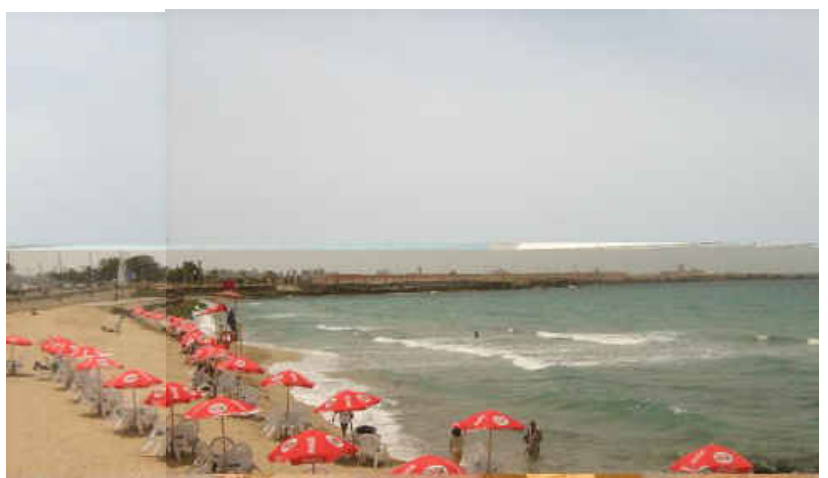

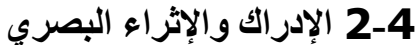
إعاقة جزئية للرؤية العائق هنا عائق طبيعي مع بداية ظهور

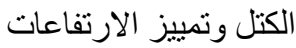

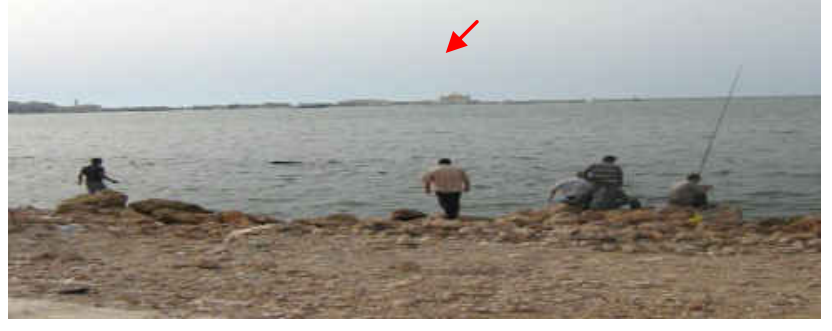

2-5 الإدراك و الإثراء البصري

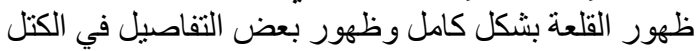
و الارتفاعات و لا توجد عو ائق للروئية

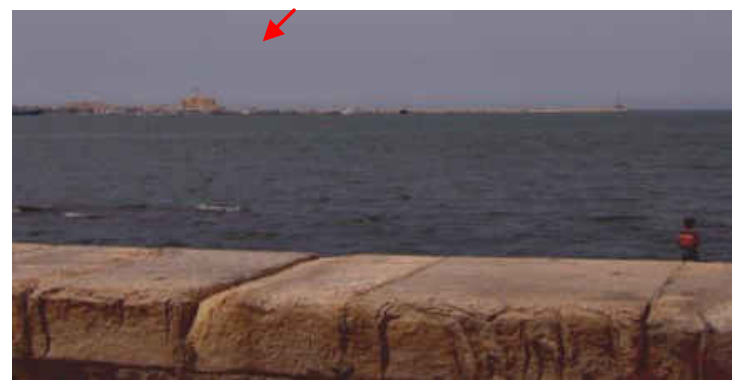

6- 2- 2الإدراك ولإثراء البصري

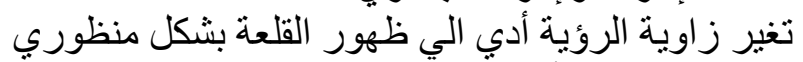

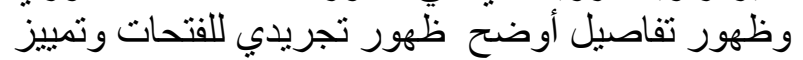
الألوان و البروز ات و والظعلال
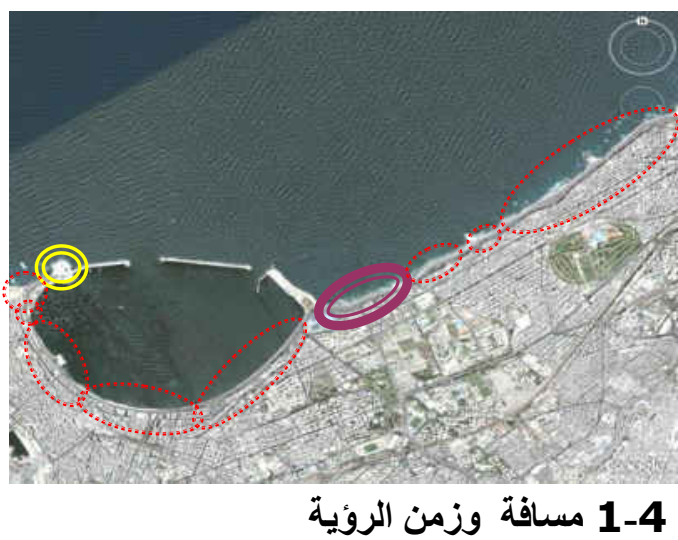

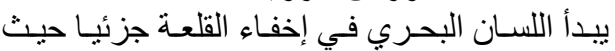

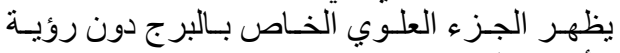
الأسوار المنخفضة نسبيا

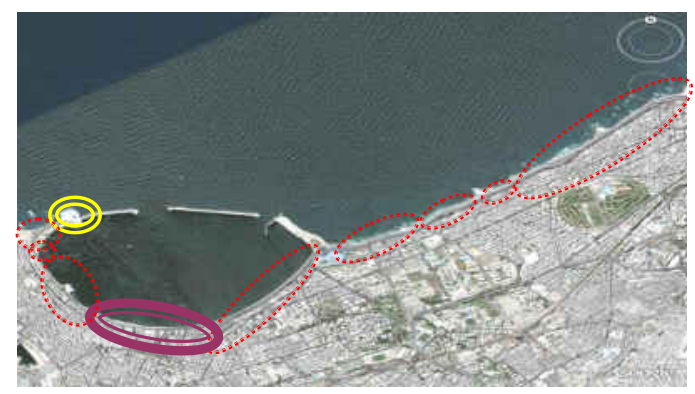

1-5 مسافة وزمن الروئية

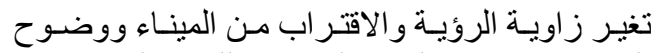

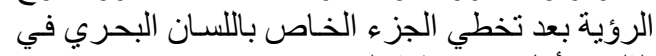
التلث الأول من منطقة الميناء الخياء

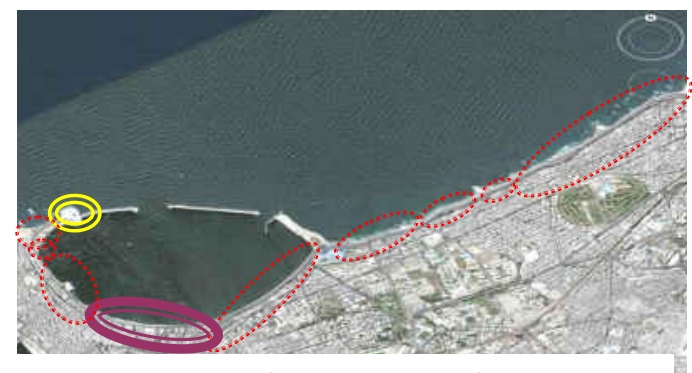

\section{1-6 مسافة وزمن الروئية} الاقتر اب من المبني و الاقتر اب من الرونة الميناء الثرقي وتغير زاوية الرؤية في الثلث الثن الثن الثناء الثاني من منطقة الميناء 
4-3 المتتابعة البصرية لمبني قلعة قايتباي علي طريق الكورنيش

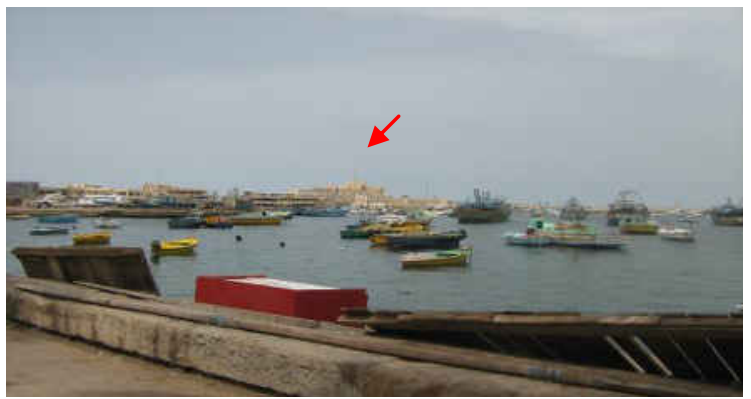

2-7 الإدرالك والإثراء البصري

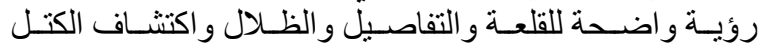

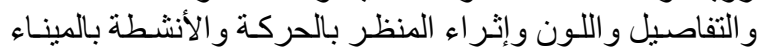
التي تضيف الحيوية للمنظر التزر المنظ

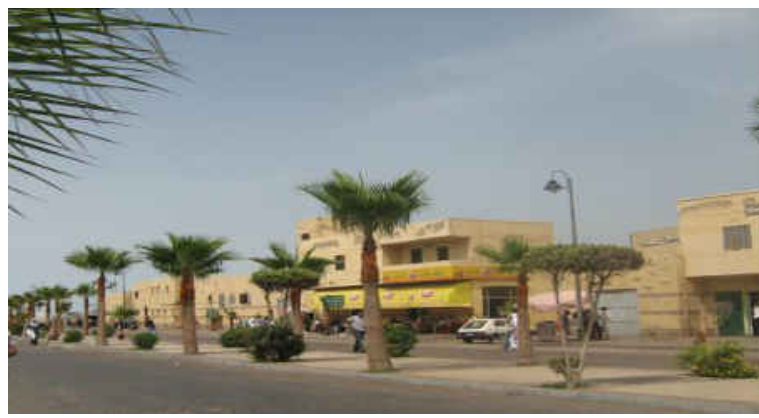

$$
\text { 8- } 2 \text { الادراك والإثراء البصري }
$$

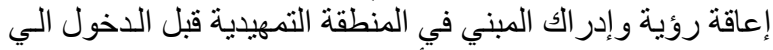

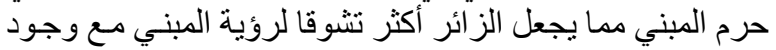
صفوف النخيل الموجهة للحركة

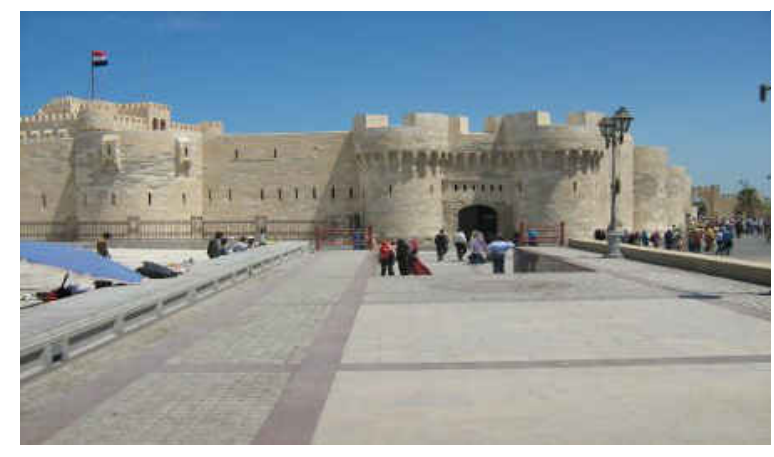

9- 2 2الادراثك والإثراء البصري

رؤية القلعة كاملة بعد التشويق للرؤية في المرحلة السابقة الكتل

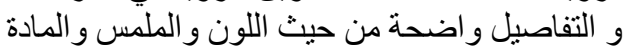

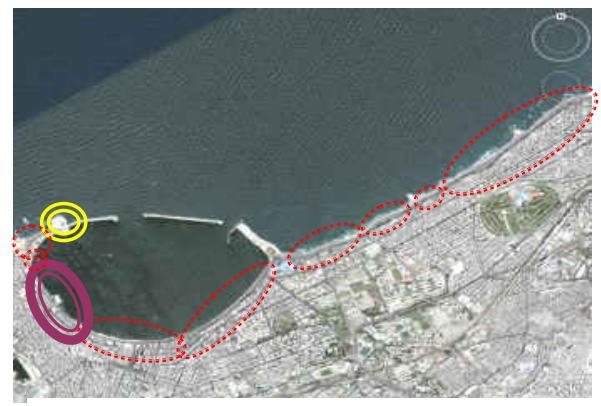

7- 1 1 1مسافة وزمن الروئية

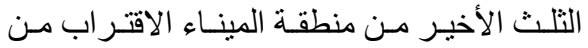
مبني القلعة وتغير زاوية الرؤية
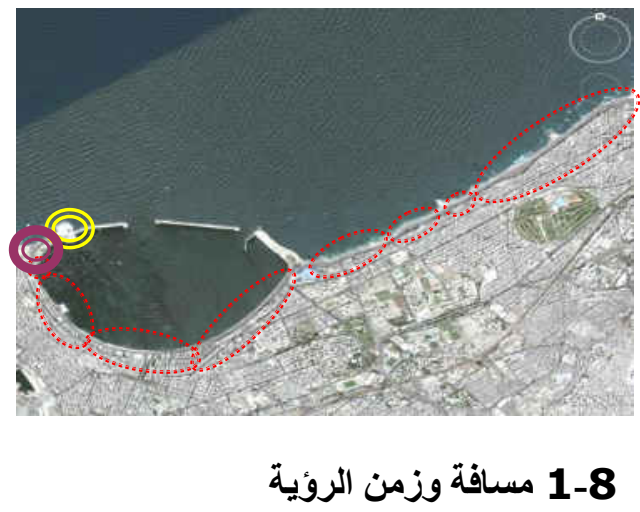

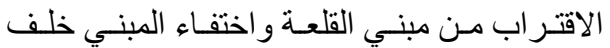

المنشآت الخاصة بالميناء التي اتخذت الواء الوان مشابهة لألو ان القلعة وارتفاعات منخفضين الخياه

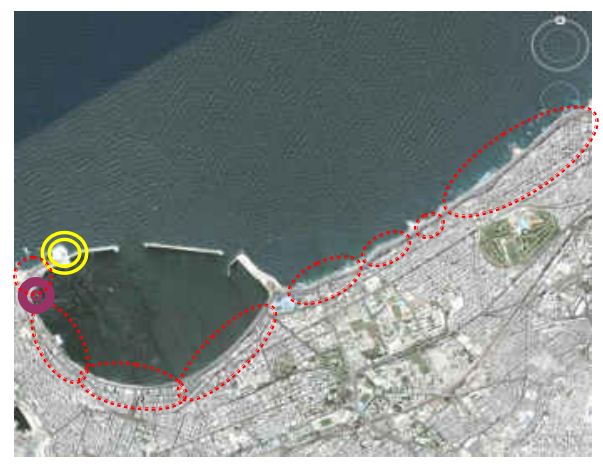

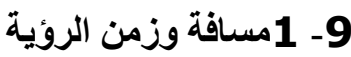
الوصول الي نقطة الرؤية الكاملة الو اضحة للمبن للمبني و الاقتر اب عن طريق مدخل المشاه 
5-3 التجربة البصرية داخل النطاق العمراني لقلعة قايتباي

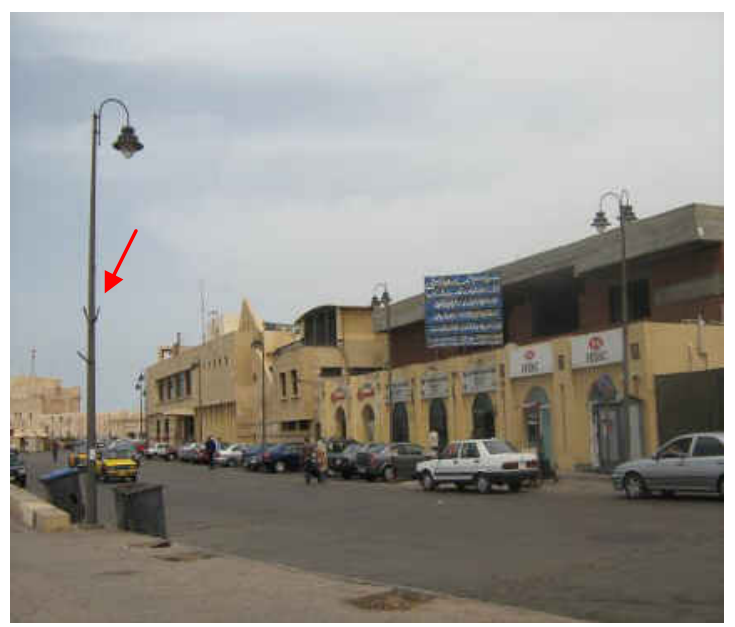

من خلال الجولة البصرية داخل نطاق القلعة تبين الأني :1-5-3 إنخفـاض المبـاني المحيطـة بالقلعـة حيث لا تتعدي الارتفاعـات المحيطة بـالمبني

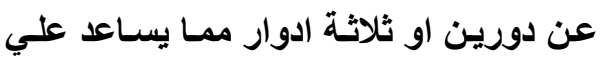

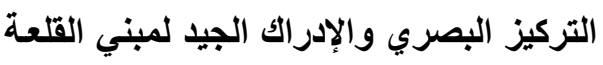
شكل (6) يوضـح انخفـاض المباني المحيطة بمبني القلعة .

شكل (6) انخفاض المباني المحيطة بمبني القلعة . (تصوير الباحثة )

2-5-3 يلاحظ أن في المباني المتاخمـة للقعة تم استخدام مواد البناء والألوان المتناغمـة والنسب

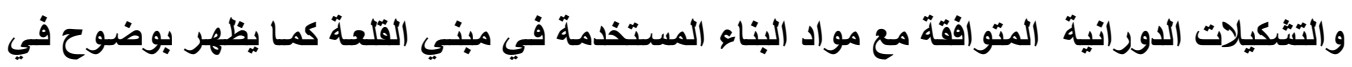

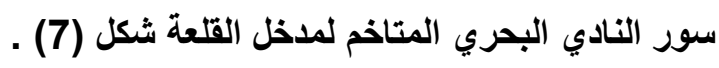
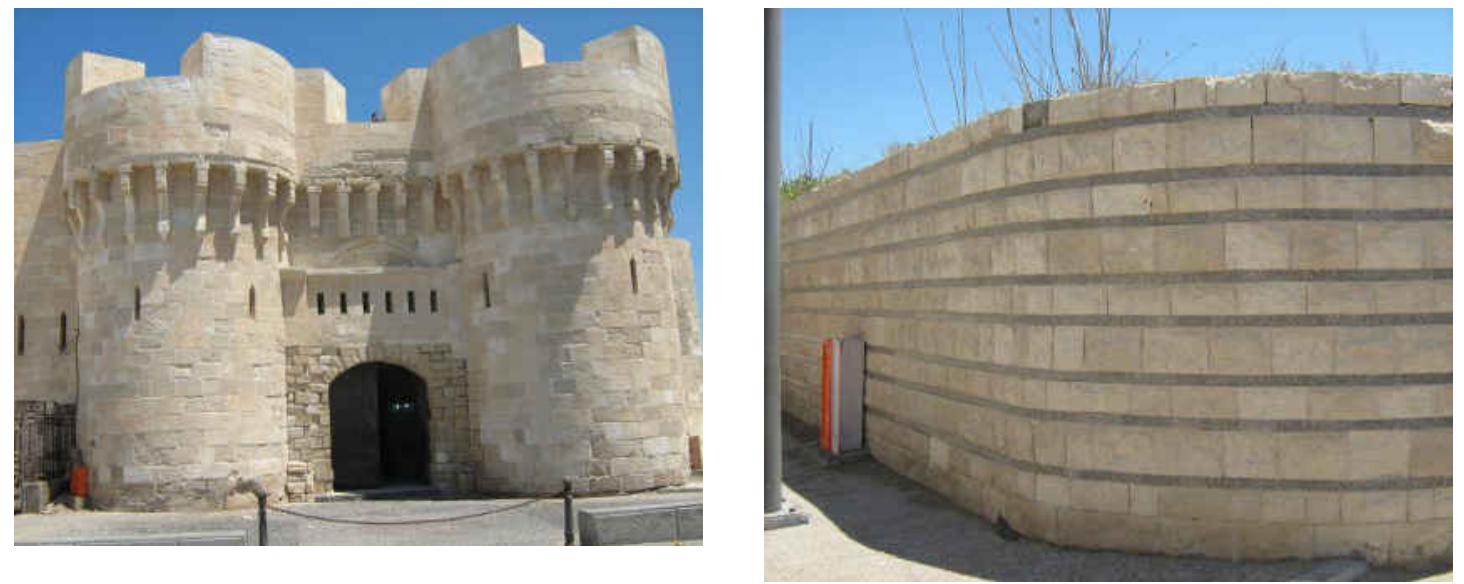

شكل( 7-أ) سور النادي البحري المتاخم للقلعة شكل (7-ب) مدخل السور الخارجي لقلعة حيث نلاحظ التتاغم و التو افق في مو اد البناء و الألوان و النسب و التنكيلات (تصوير الباحثة ) 
3-5-3 ظهور مدي الحاجـة إلـ الاهتمـام والصيانة المستمرة للمباني المحيطة بالقلعة ، ليتم إثراء التجربة البصرية بالمنطقة ، حيث أن إهمال المباني المحيطة دون صيانة يؤدي الي تثنويه المنظر

شكل (8) (1)
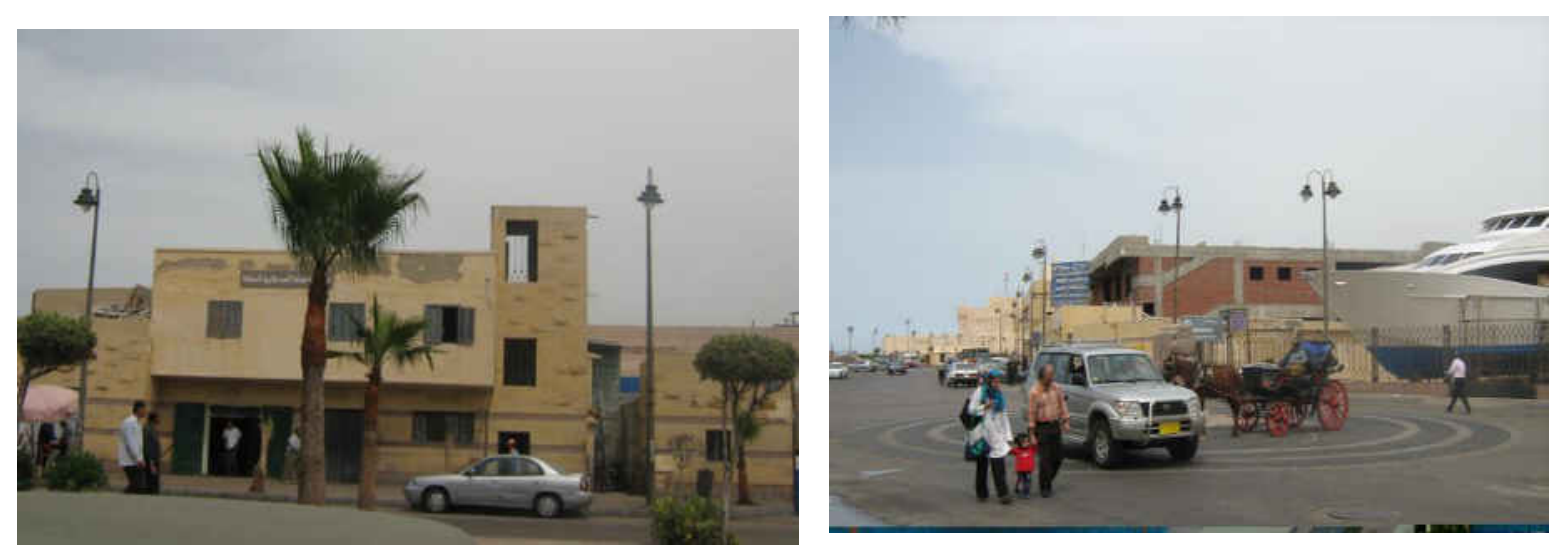

شكل (8) أهمية الصيانة و الحفائ علي الثكل اللائق للمباني المحيطة

4-5-3- أهميـة الحفـاظ علـي الطـابع القديم التـاريخي للمبـاني المحيطة بالنطست الأثري وضـرورة

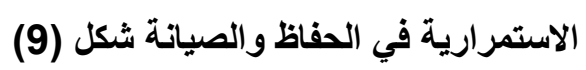

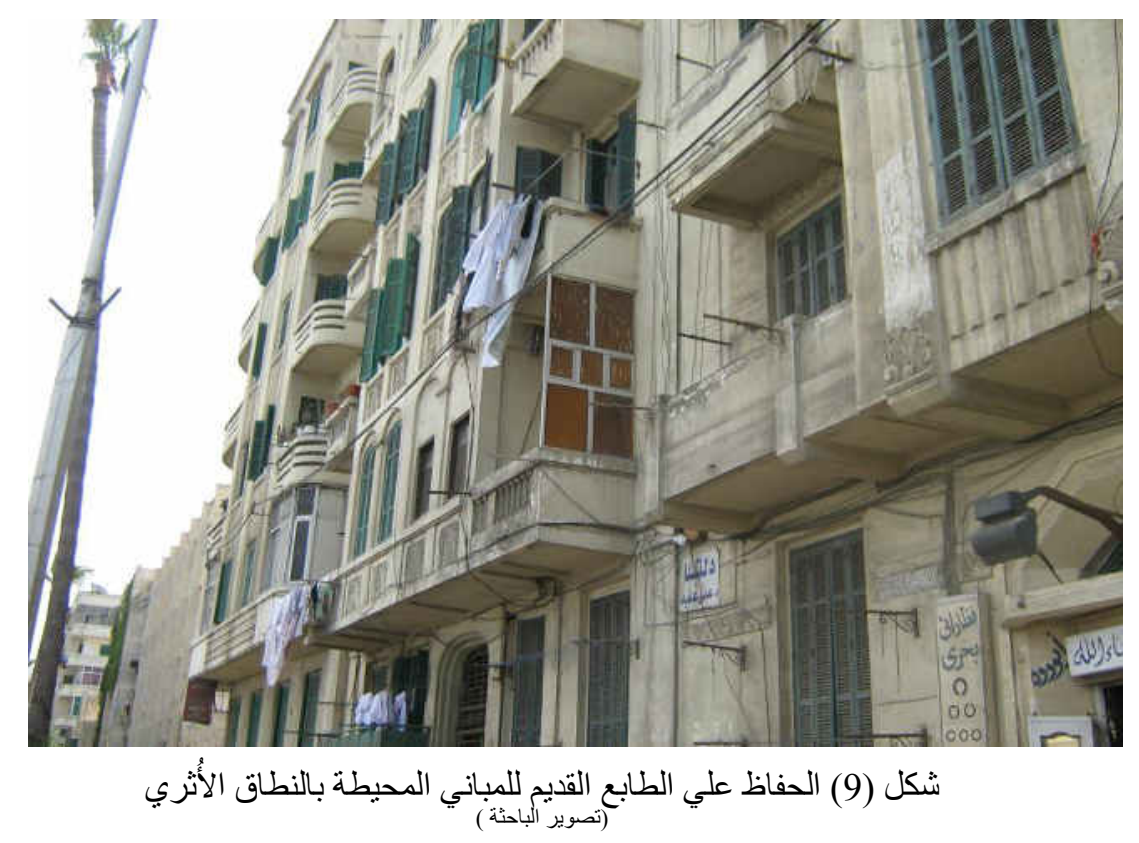




\section{5-5-3-5 الاهتمام بفرش الفراغ الحضري أمام وحول المبني بالقلعة}

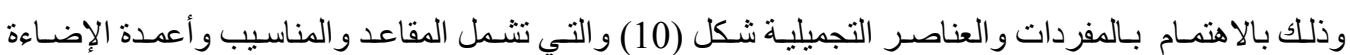

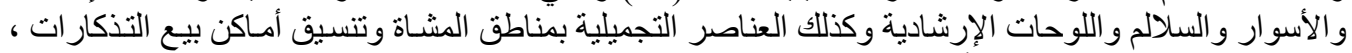

ومنع البائعون الذين يفترشون الأرصفة ولوحظ نقص الاهتمام بالمناطق الخضر اء وتنسيق النباتات شكل (11)

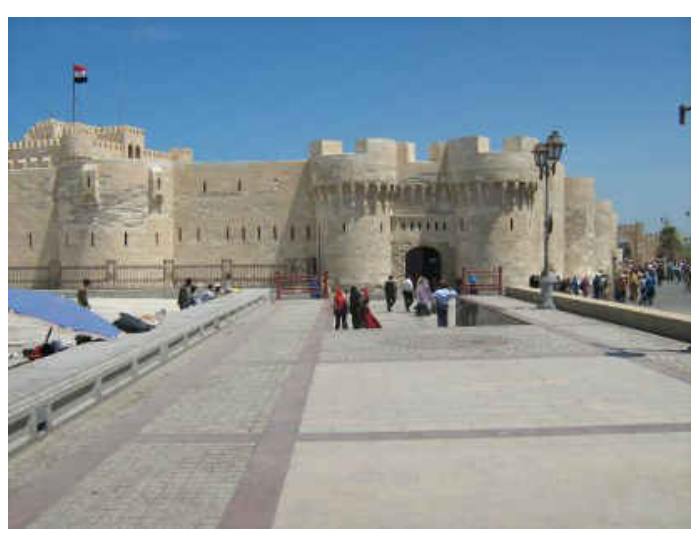

شكل (11) نقص الاهيما بتنسيق النباتات بالموقع

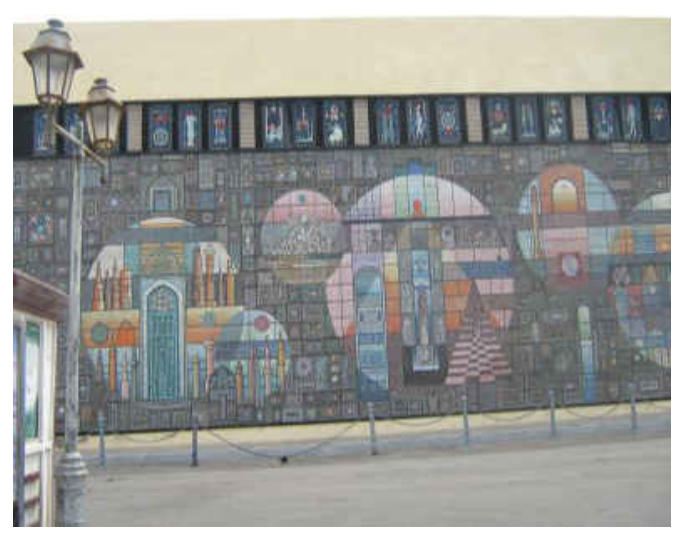

شكل (10) الاهتمام بالعناصر التجمئزة) التجية لإثراء الموقع

\section{4- خلاصة وتوصيات البحث}

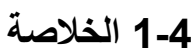

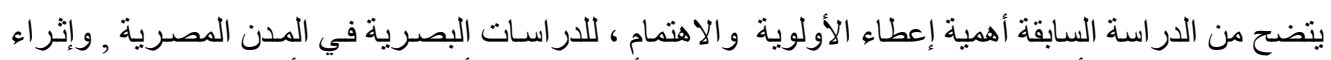

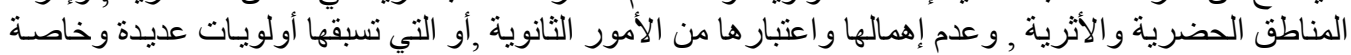

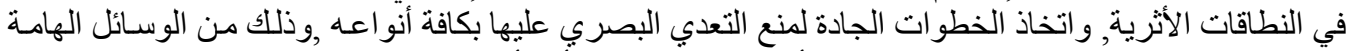

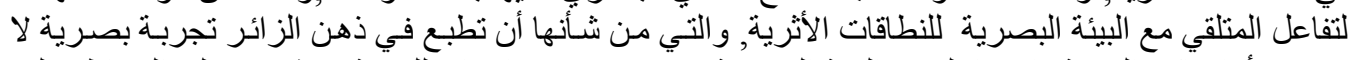

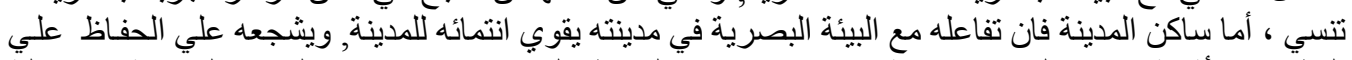

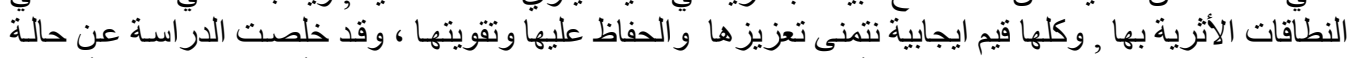

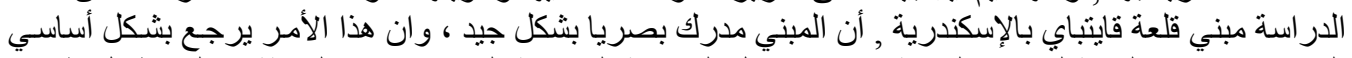

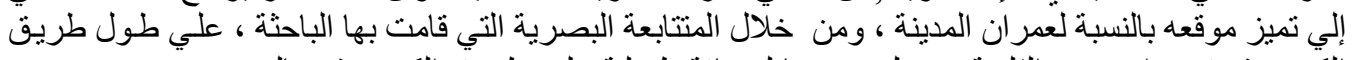

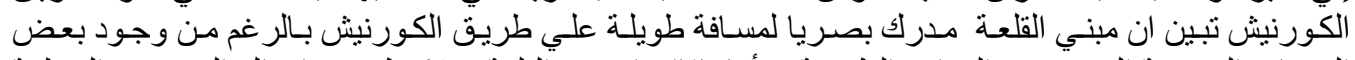

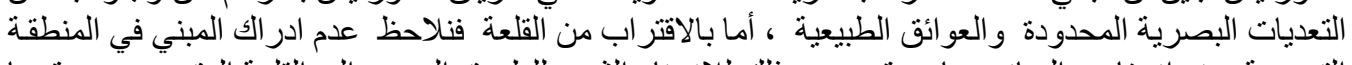

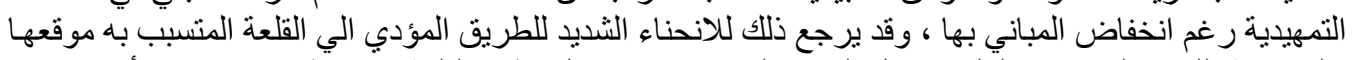

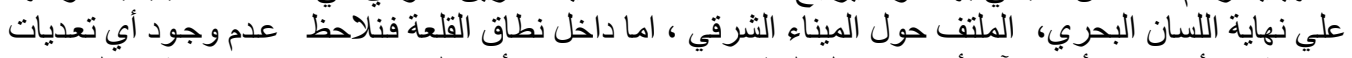

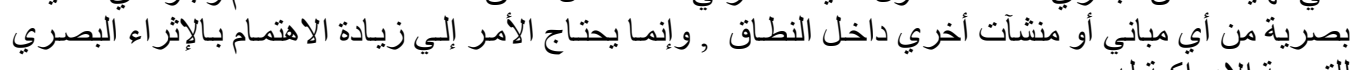
لالتجربة الإدر أكية له . أله

\section{2-4 - 2-4 توصيات البحث}

من خلال الدراسة السابقة نري انه من الواجب الاهتمام بتحقيق الإثراء البصري للنطاقات الأثرية من خلال منهج عمل يتحقق عن طريق الخطوات التالية :

\section{اولا الحفاظ والحماية والصيانة للمبني الأثري ذاته}

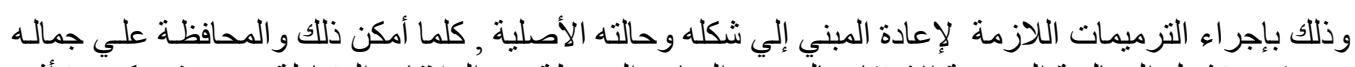

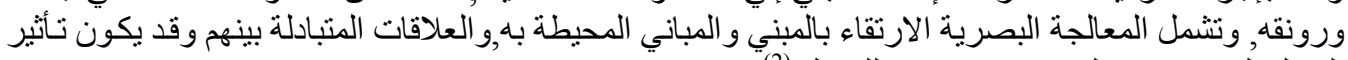

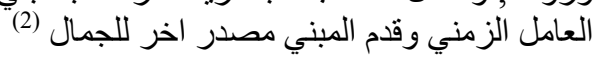




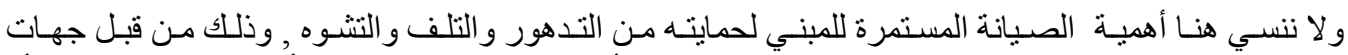

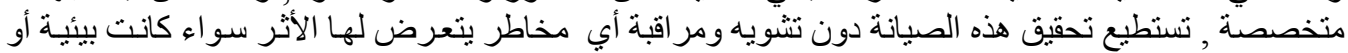

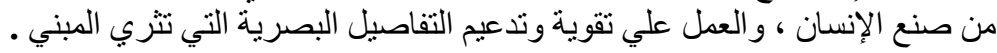

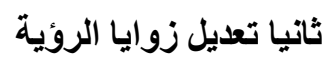

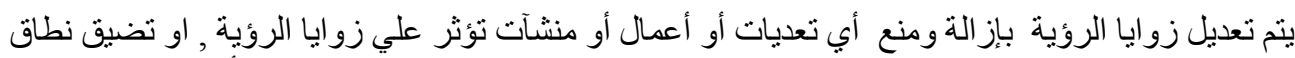

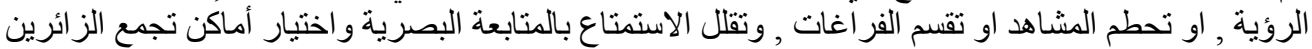

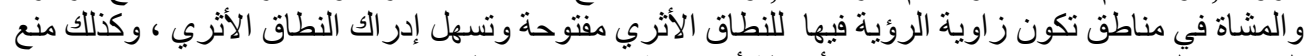

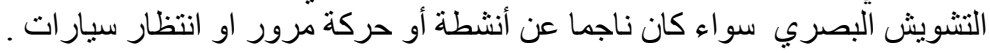

ثالثا معالجة النطاق العمر اني المحيط

يجب معالجة النطاق العمر اني المحيط , بحيث يحقق التكوين العمر اني المحيط بالمبني الأثري الهدف المرجو منسه المبه

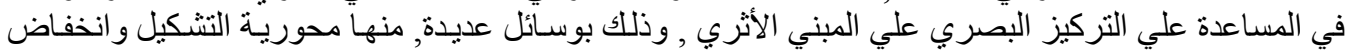

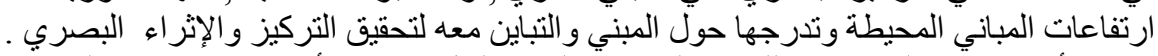

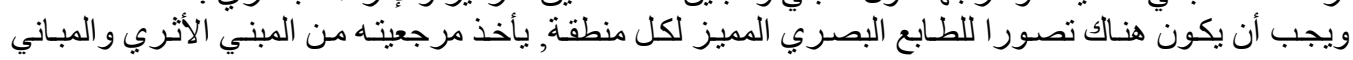

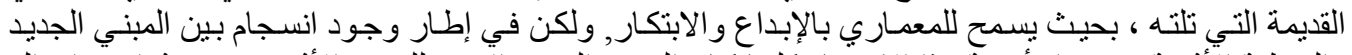

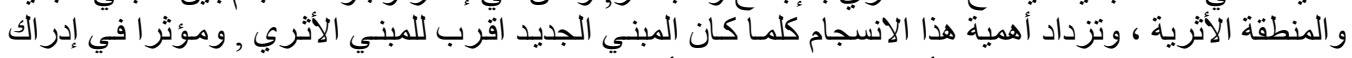

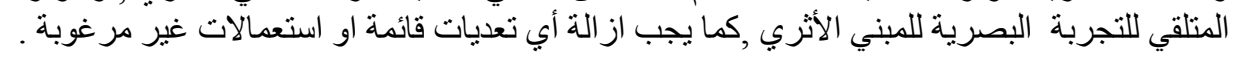

\section{رابعا تنسيق الموقع}

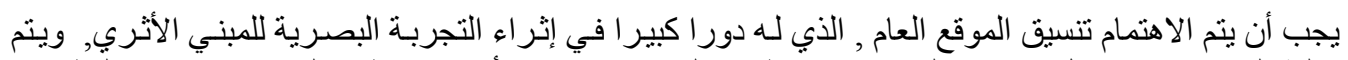

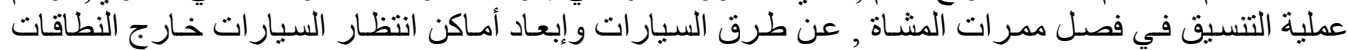

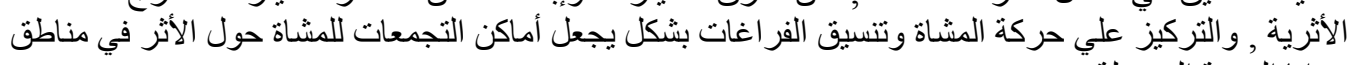

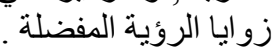
كذللك يجب بالنسبة للفرش المعنة المعاري, ان يتم عمل تصميمات خاصة للفرش المعمارية لكل منطقة أثريـة بمـا يلائم

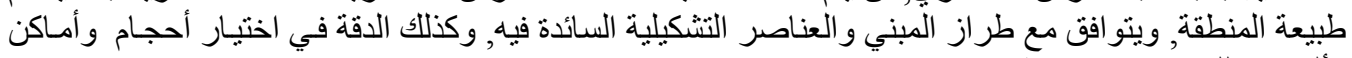

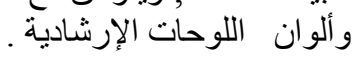

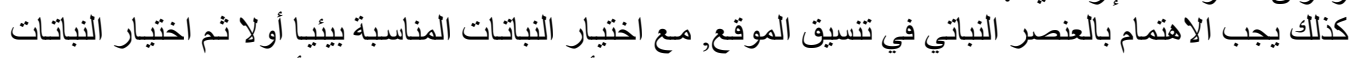

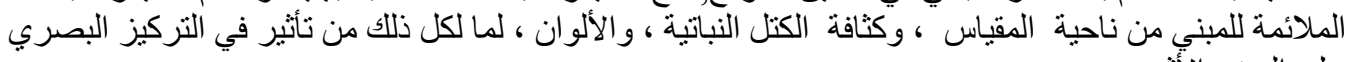
علي المبني الأثرِي

\section{خامسا الاهتمام بالتوعية البصرية للمناطق ذات القيمة الأثرية}

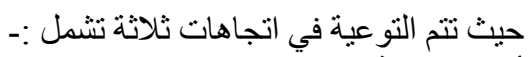

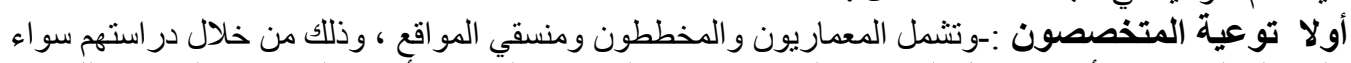

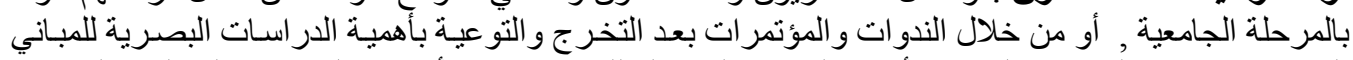

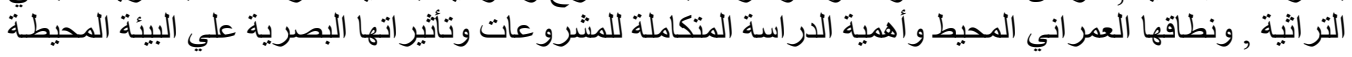

ثذاتيـا توعيـة التشريعيون والتنفيذيون: - وهي الجهات التي تقوم بإصدار القوانين وتنفيذها وتوعيتهم بأهميـة

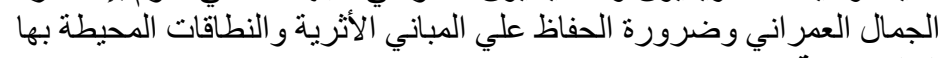

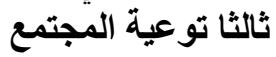

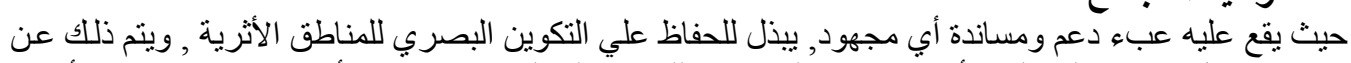

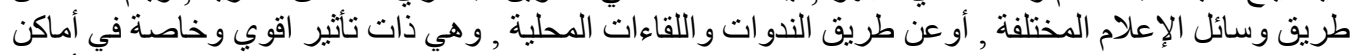

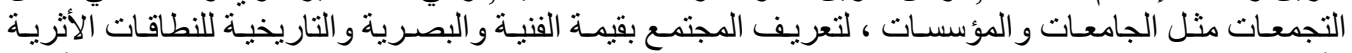

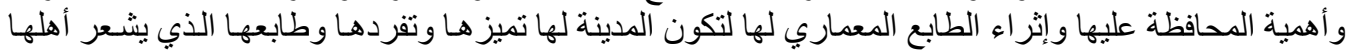
بالفخر و الانتماء لها. 


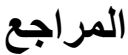

(1) Bentley Alcock , Murrain McGlenn Smith. Responsive EnvironmentsArchitectural Press - Elsevier Science - 2003

(2) احمد عبد الوهاب السيد - صياتة وإعادة استخدام المباني الأثرية وذات القيمة ـ رسالة ماجستير - جامعة القاهرة - 1990)

(3) احمد فريد مصطفي ـ تناغم بصري وفراغي دراسة لبعض الطرق الرئيسية في المدينة المنورةـ مجلة البناء

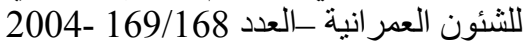

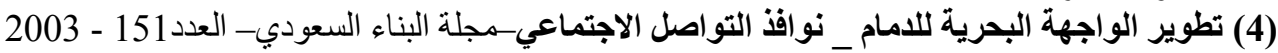

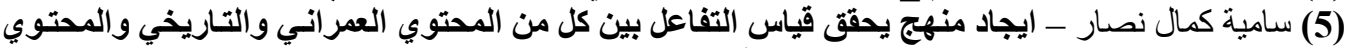

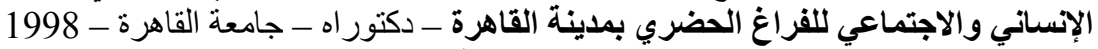

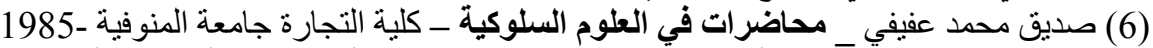

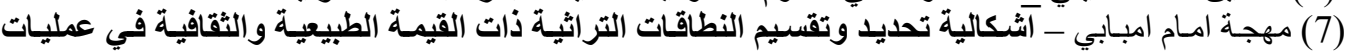

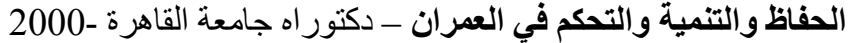

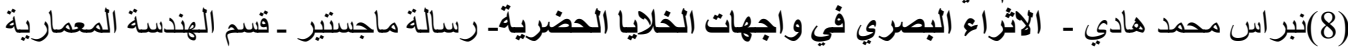
ـ الجامعة التكنولو جيةـ بغداد - 2002.

(9) وسام محمود حسين - التصميم البصري للفراغات العضرية بالجامعة - رسالة ماجستير ـ كلية الهندسة ـ-

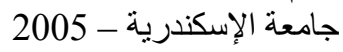

(10)http://auiss-eng.org/2005A.htm

(11) http://farm1.static.flickr.com/172/447466631d3aa3b5b3d_o.jpg

(12) http://pr.sv.net/aw/2005/julay/arabic/news3.htm

(13) http://nadi.alkahf.com/view_uploader.php?do=get\&id=10804

(14) http://www.sis.gov.eg/Ar/Arts\&Culture/Archaeology/islamic

(15) http://www.tkne.net/vb/archive/index.php/t- 21346.html

(16) h1ttp://www.sis.gov.eg/Ar/Arts\&Culture/Archaeology/islamic 